\title{
The Dance of Becoming: Pedagogy in Dance/Movement Therapy in the United States
}

\author{
Valerie Blanc ${ }^{1}$ (D)
}

Accepted: 17 August 2021 / Published online: 8 November 2021

(c) American Dance Therapy Association 2021

\begin{abstract}
The purpose of this study was to begin to define pedagogical theory and practice in the field of dance/movement therapy (DMT). Fourteen DMT educators from American dance therapy association approved programs participated in the study, taking part in individual semi-structured interviews through a phenomenological lens. The participants had taught in the DMT field for at least five years and at most 44 years. Utilizing grounded theory methods, two focus groups were also conducted in which six DMT educators discussed initial qualitative themes from the individual interviews. Through an engaged process, participants were able to participate in the further defining of the study's themes. Data were analyzed using grounded theory methods of initial and focused coding. The researcher also used member checking, peer review, and a personal research journal to name her own reflexive position within the emerging data. The researcher's findings centered around six qualitative themes. These themes named the importance of the DMT student's development of self-awareness including body identity, cultural identity, and professional identity all housed within the experience of embodied learning. Findings also named the importance of educator transparency and modeling in the classroom to create space for student exploration. Recommendations from the study aimed towards creating more opportunities for educators to collaborate and communicate across the field with the goal of creating best practices for DMT education. Also recommendation for DMT educators centered around clarity of expectations in the embodied self-reflective learning process.
\end{abstract}

Valerie Blanc

vblanc@lesley.edu

1 Department of Expressive Therapies, Graduate School of Arts and Social Sciences, Lesley

University, 39 Everett Street, Cambridge, MA 02139, USA 


\section{Introduction}

The landscape of dance/movement therapy (DMT) training and education in the United States is entering a substantial and vibrant time of change and adaptation. Training programs in the United States are growing rapidly both in number of programs and numbers of graduating students. These new practitioners bring with them innovative ideas and calls for social action that are shifting the field in necessary ways. For example, the multicultural diversity committee affinity groups within the ADTA have continually voiced needs for members be seen fully within the organization and within their training programs from their intersectional identities (Thomas \& Blanc, 2021). At this important juncture, DMT educators, have a responsibility to meet the needs of these new colleagues. This time holds an opportunity to examine the teaching practices of the field and explore how educators are using pedagogical practices in the classroom.

In 2017, the educational standards of the American Dance Therapy Association (ADTA) were revised to reflect important changes in the training of dance/ movement therapists. ADTA approved programs have until 2023 to come into compliance with the new competency-based standards, which has afforded an opportunity to connect across programs sharing DMT teaching methods as education colleagues. This process reflects a shift in the field and potentially in the education and training of DMTs in the United States.

In the earlier days of the history of DMT in the US, DMT education focused on an apprenticeship and protégé model (Leventhal et al., 2016; Stark, 1980). DMT theories and principles were imparted from teacher to student, as students engaged with clients as co-leaders in treatment settings (Beardall et al., 2014; Payne, 2008; Sandel, 1993; Chaiklin \& Schmais, 1993; Schmais, 2004; Leventhal et al., 2016). As training programs developed further, so too did accreditation standards, professional certification, and educational standards (Stark, 1980). Most recently, education advances have included the incorporation of distance learning as a hybrid delivery model (Beardall et al., 2016). Throughout this "legacy of embodiment" (Leventhal et al., 2016, p. 166), DMT educators have utilized unique and innovative pedagogical practices which hold the potential to build a distinct pedagogical theory.

\section{Related Theories of Education}

Within the required master's level training for dance/movement therapists, course work focuses on general clinical psychotherapy skills as well as movement observation, research, and DMT theories and practice (Cruz, 2001). Along with coursework the learning process of the DMT student includes an internally focused formation of one's own therapeutic style, experienced through awareness and development of a body-self, an interpersonal self, and an intrapsychic self (Payne, 2008). Throughout the coursework, there is a continued focus on 
embodiment and relationship in practice and training to foster a deep and multilayered experience of DMT theories and practice (Chaiklin \& Schmais, 1993; Sandel, 1993; Schmais, 2004). With relationship and awareness of self and other at its core, learning for the DMT student is a process of embodied experiences, relationship, and reflection. This complex and multi-faceted process of learning in DMT education aligns with several theories of learning and teaching, including experiential, transformational, feminist, and critical foundations of pedagogy.

Experiential and transformative learning theories focus on an enactive learning process which includes the importance of disorientation (Dewey, 1938; Dirkx, 1998; Kolb 1984; Kolb and Kolb 2005; Mezirow \& Taylor, 2009). The learner engages with a new concept by comparing it to prior knowledge and going through moments of conflict and discomfort in that ontological shift. These theories align with a humanist ontology recognizing the connection and conflict between humans and the world in which they live. Humans are viewed as "beings of praxis" (Freire, 2000, p 125 ) and learn through active reflection and dialogue, all of which requires a sense of humility.

Similarly, Vygotsky's (1978) theory of socio-cultural learning centralized the idea that humans do not learn in isolation but that they learn by interaction within their social environment (Daniels, 2003). The educator's responsibility is to offer active and interactive learning situations where the student can engage both on a societal and personal level. This theory, similar to transformative learning, holds the belief that students compare new information to previously held knowledge, specifically content from their communities and from their individual history.

Critical and feminist pedagogical theories view learning as not only an adaptation of knowing but a reorganization of the system as a whole (O'Sullivan, 2002). These models embrace the state of discomfort and conflict, similar to transformative learning theories, yet also include a knowledge of oneself and one's place in the larger world. In order to embrace values of inclusivity in the classroom, educators from this viewpoint must recognize the legacy of teaching from a "single norm of thought and experience" (hooks, 1994, p. 35). Viewing learning through a critical lens, there is an awareness of students' lived experiences and personal development in culture, society, and communities and how learning can be used as a social change agent to push against the larger systems at play and disrupt the idea of a single ontological narrative (Miles, 2002; Selby, 2002; hooks, 1994).

Expressive therapy scholars have also voiced the need to include these critical lenses in practice and pedagogy (Chang, 2009; Caldwell, 2013; Hadley, 2013; Hahna, 2013; Allegranti, 2009; Sajnani, 2012). Increased awareness and transparency around dominant narratives in art forms, viewpoints of health and therapy, and ways of teaching are necessary to liberate the expressive therapies from embedded cultural narratives and centralized, singular norms (Hadley, 2013; hooks, 1994). This process calls for an examination of the unconscious and invisible nature of aesthetic and health-related narratives often held by the dominant identities who hold power in those spaces. This requires educators to actively explore their own position and experience of power and privilege within their roles (Chang, 2015; Hadley, 2013; Hervey \& Stuart, 2012). In order to create that space and transparency of identity, the therapist needs to be aware of cultural representation within their art 
form, their client's view of health and healing, as well as social location and experience (Sajnani, 2012).

In its practice, education in expressive therapies can shift the power differential in the classroom, using the arts as a mode for individual and social change (Hahna, 2013). hooks (2003) similarly urged educators to shape their classrooms through a democratic lens, sharing and acknowledging the limits of their own knowledge. The instructor steps from behind the lecture podium, moving and experiencing alongside students emphasizing relational and democratic learning (Hahna, 2013; hooks, 2003).

Teaching from a relational foundation, as many theories outline, there can arise issues of role confusion for the student which several expressive therapies scholars have identified (Lusebrink, 1989; Emunah, 1989; Butler, 2016). The tenet that learning comes from a personal experience of the work can blur the boundaries between teacher and student as well as the boundaries between personal and universal experience. Expressive therapy educators often communicate to their students that their education is not therapy, yet expect personal exploration within the context of embodied and experiential learning. Butler (2016) explored this question of the line between education and therapy in his phenomenological study. His student participants shared a perception of expectation to share emotional experiences in their training program, which needed to be navigated carefully and skillfully with a sense of shared responsibility.

The learning experience of DMT students is contained in kinesthetic, affective, and experiential embodied experiences. As Meekums (2006) wrote, embodiment is an "active source of knowledge production" (p. 169). Through research of DMT's pedagogical foundation, there is an opportunity to define a "body of theory" (Stark, 1980, p. 15) in DMT pedagogy. As instructors strive to give students experiences of their own inner sense of body and outer sense of others, how are classroom interactions translated into practice (Beardall, 2011; Hervey, 2007; Schmais, 2004)? These questions were explored in this qualitative study.

\section{Research Question}

This study's purpose was to explore the classroom experiences of DMT educators in the US to discover common themes and begin conversations across training programs. This study explored the pedagogical practices of DMT educators in the United States, with the research question "What core principles of theory and teaching strategies contribute to pedagogical theory in DMT in the United States?".

\section{Methodology}

The researcher used a phenomenological perspective to address this question, connecting with DMT educators and their experience of teaching to gain an understanding of shared experiences of DMT educators (Caldwell, 2013; Vagle, 2016). The researcher recruited educators across the seven ADTA approved DMT programs, 
recruiting two or more participants from each program. Participants had experience teaching in a graduate level approved DMT program for at least five years, and there was no upper limit of experience.

Each participant engaged in a semi-structured interviewed either in person or via Zoom, which were transcribed and analyzed through focused line-by-line coding. Participants were invited to engage in movement elicitation before the verbal portion of the interview, with the purpose of accessing kinesthetic memory, description, and embodied experiences (Goodill \& Schelly Hill, 2017).

The researcher then invited the study participants to participate in two focus groups. During the focus groups, the researcher presented six categories that came from the initial coding process to the focus group participants. The researcher asked the focus group participants about these themes, how they fit into their own teaching experience, and if there was anything missing from the qualitative themes. Using a grounded theory perspective, the participants were able to participate in the further development of the pedagogical themes from the study. The interview and focus group data were analyzed through initial and focused coding to further define nuanced experiences of the core principles of DMT and their interrelatedness with the six categories.

\section{Results}

The 14 individual interviews yielded six categories, and 28 subcategories. These six categories were presented to two focus groups, consisting of three participants each, where participants could discuss concepts of DMT pedagogy in further detail and clarify definition of the categories. Any words or phrases in quotations are taken from interview transcripts to capture the voices of the participants.

\section{Self-Awareness and Growth}

Most often mentioned was the way in which self-awareness developed for the DMT student throughout their educational experience, coded as self-awareness and growth. The relational aspect of psychotherapy was at the foundation of this theme as one participant said, “if you don't know about you, you don't know what you're putting out to the world so it's self-awareness in the service of helping others". Another participant stated that, "the way we do therapy is to use deep parts of ourselves and ... to be fully present at the body/mind level while moving". This skill, according to the participants, requires a process of knowing the self on multiple levels.

Adult development was an important subcategory, that was mentioned by 11 out of 14 participants. They spoke about the differing developmental levels from which each student entered the training program and how they viewed each student along a developmental arc as they moved through the program. This ranged from a young adult stage where students are grappling with questions of their 
own identity to students learning to let go of prior knowledge in order to engage in a "beginner's mind" in this new unique learning environment, that "provides for a way to learn anew".

Development was also addressed in the arc of a program, and how students developed throughout the scope of their two or three years in a DMT graduate program. As one participant said, "we're not talking about soaring in the first year" and "the first year is about building blocks ... some knowledge that has to happen and some basic skills that have to happen". Pedagogical tools focused on ways to gradually allow students to engage in more abstract ways of thinking. Participants spoke of first year students' common desire to engage with more clear expectations, cognitive learning, and explicit information in the classroom. There was also an awareness of the potential overwhelm that students may feel and the need to "titrate" or give "gradations of information and experience" so that students can embody this epistemological shift. Earlier in their development, students often hold onto concepts in a cognitive way and are not yet be able to integrate that knowledge in their bodily experiences. Other participants called this the desire for "skill set" and how difficult that can be for some student to release. One participant spoke finding a way to "find self, which we're building identity ... it becomes the ways you build self and then some of those skills start to fit you".

The shift from artist to therapist identity was reflected, reframing for the student how movement is understood and implemented. Cultivating presence in a movement interaction was a "process of careful, careful learning and training yourself to put yourself in the background", which is a potential challenge for those coming from a performance background. One educator spoke of the need to look at your own assumptions about movement and relationship to movement to be able to "see the patient and to see the patient's movement" from a holistic place. Coming from a role as a dancer/artist made it a harder practice for students to embrace the "idea of connecting emotion with a movement or an experience with a movement". Student may be "extraordinary movers" but their own selfawareness around dance as therapy may be a growing edge.

Struggle and conflict in the classroom both with peers and within themselves was another area of growth. Participants spoke of students' ability to release their expectation for didactic lecturing from their instructors. “... Because our work is geared towards, self-growth and development ... I need the students' involvement and engagement to sort of take ownership, to help create that environment where everybody can ask for help and grow together". Group dynamics shaped the students' self-awareness because "you're not doing this in a vacuum, you're not doing this in isolation". Students' experiences of themselves were shaped by everything that was brought into the group dynamic and often gained as much from peer interactions as much as instructor intervention.

Participants spoke about the "different sort of quality of personhood" for the DMT student, personhood being the awareness of one's individual identity. This process was facilitated by assignments and classroom environments where the focus was introspective. 
I feel that the teaching of dance therapy is a very unique and specific process because it's not about learning, it's about becoming which is a very different process. And the part of the student that you're teaching to in order for them to become a good dance therapist is, it's buried, it's not on the surface. It's not cognitive. It's the real essential psychic core of the person that you're teaching to.

As DMT students learned to stay in tune with both the cognitive and the embodied parts of themselves, they begin to learn the skills necessary for clinical work in application. "They stay in tune with their moving, intersubjective, empathic, right brain selves but are also intentional, informed therapists". One participant stated this process as follows,

It's really, it's one of my favorite parts, because ... it's this really transformation where they've been so cognitive ... (and) entering internship...coming from this place (of) whatever their idea of a dance movement therapist, however, a therapist should look, and should act, and should be in the setting ... And then there's this beautiful shift that happens, where they're like 'How do I bring in me?'

Focus group participants also reiterated the developmental trajectory that students experienced and the importance to recognize and validate that process for students. "Being a learner is a vulnerable period of time and ... you know, kind of validating the students' experience of being a learner and how hard that is". The trajectory was also reflected by one group member who said, "I think that what I notice in second year is, they're so gracefully aware of their internal lives in a way that they don't have that access when they first come in". Participants also shared a belief that the self-awareness process was different than other fields due to the addition of bodily experiences and body awareness. "Because it is so vulnerable and we're asking people to go there that it already takes it to the next level".

\section{Culture, Diversity, and Social Justice}

The theme of culture and diversity connected deeply to both students' and educators' processes. Participants spoke about culture and diversity issues in both their students' experiences and their own personal experiences. Three participants named social justice frameworks as a core tenet to their own teaching philosophy.

This parallel process of educator and student was reflected as participants spoke about ways "experientials build awareness" giving student opportunities of "how they might work with that in and through the body and with each other". Other also spoke of moving beyond individual teaching moments and focusing on trainings for educators.

So this year it was and the year before that, you know, every meeting, every training, every everything I went to was about that (culture and diversity) so maybe it's, maybe it's more part of my lens, maybe it's embodied. 
The revised educational standards include the skill development of communicating "intrapersonal and interpersonal movement patterns through a culturally informed" lens (ADTA, 2017, p.22). One participant spoke about the process for students of understanding one's own movement signature in relationship to one's social location and experiences.

How is my, my movement being impacted by my own background ... that it's beyond this specific interaction ... We're studying of course movement signatures and movement signatures seeing both of ... echoing the cultural imprints of your context so you can have a sense of belonging somewhere ... Uh, it's very important to be aware, knowing what your background is, or where, what your movements signature or how has it been informed in the past? As well as what has been allowed, depending on ... your own location.

The idea of exploring the concept of movement signature through a cultural lens, for this participant, helped to shape the students' awareness of their own movement in the world as well as their own cultural lens.

When discussing teaching methods, participants shared struggles around addressing the marginalization of cultural dance healing practices in courses. There was a shared challenge around how to teach DMT's theoretical frameworks while still allowing space for critical questioning of the centering of certain theories. Educators in the study spoke about the challenge of "holding on to these amazing, amazing truths about movement while still re-looking at them. And while always holding ... the primacy of context". Participants spoke of owning the fact that the field of DMT was founded primarily by white cisgender women and comes from a "white European female lineage". There is as one participant said, strengths to that and how to "recognize the strengths and also just like tracking the history of how counseling changed how psych(ology) was initially a white male profession and now woman, female dominated". At the same time also honoring as another participant said, "what are the shadows or the underbelly of that? ... we talk about how to bring how to bring a kind of a wholeness to the discussions about history and what does it mean now, in this day and age?".

Participants, 13 out of 14 of whom identified as white, spoke of their passion and focus on learning "how to do it better" and the opportunity to "(engage) in a lot of conversations with different colleagues....across programs". There was, however, a common sentiment of feeling that this content area was a growing edge in their teaching.

I feel like that's, really a growing edge for me as a teacher ... and our students are beautiful in their readiness to explore, and question, and share their experiences, and challenge the assumptions of the field, or my assumptions as an educator. And and it's a rich and evolving part of our shared space ... This is emerging (for me)

Participants spoke of the challenge and discomfort in this process of learning for themselves and for their students, similar to the learning process of DMT at its core. 
It's a work in progress ... the more I can integrate for myself, the more I can bring that integration to the classroom. So I think that's my that's one of my goals, I think, it's to help to help integrate, but also to differentiate and to point out and hold curiosity and questions ... Yeah, it feels, I mean, sometimes it feels fluid (and) sometimes that feels really disjointed and uncomfortable and hard and feels like that's all part of it.

Educators spoke about a process of learning through mistakes, "I had to just really go into my own work and really commit to it and unpack it. And it was painful at times, to look at my own privilege and the places where I didn't see that having an impact on others, and especially in the classroom". Participants spoke to the importance of learning and making repairs in their own teaching. "I learned not to, just in my place of power, to sit and own the places that I didn't see and make repair, make attempts at repair was really powerful". The balance of embracing the questions of the process of cultural humility was something that participants felt important to share openly with students in the classroom. "I feel like there's, so much strength in that as teachers to show our, like, the vulnerabilities there and to own them to take responsibility for those maybe the gaps that we, maybe we see in ourselves".

Participants also reflected on the students' level of awareness culture and diversity, embracing the fact that teaching from a lens of cultural awareness brought up intense emotions for students, no matter where they were on their continuum of cultural awareness. "The first year is so much about experiential self de-construction or deconstruction of the self; which is extremely painful in many ways. But it's really great this uh ... capacity to get ... better at noticing when you're off, what's being triggered". This was another area of learning about which participants witnessed along a continuum. They were able to acknowledge the fact that "each person has their own developmental process within the program and I think you can achieve a competence".

With this process of developing awareness, challenging emotional experiences also came up in the classroom. A shared experience was one of fear of being with a sense of discomfort and potential conflict. Participants who spoke about fear were usually speaking about students who were less aware of their own cultural location. Also there were students who initiated critical conversations in the classroom. Participants said that students in recent years in their programs were bringing a "real passion for ... the diversity and inclusivity work ... we're seeing that being mirrored back ... a need to have more dialogue about it and need to have a space for it and um a demand for it". These student stories tended to be from students who were more culturally aware, yet felt conflict with the DMT field.

Well, so it's all across the continuum. I've encountered students who were angry and rejecting and disappointed when they came into the program, wondering if they could ever see themselves in this profession, um ... So trying to work through some of that and balance what my contributions could be.

As was mentioned before three participants stated that diversity and social justice frameworks were at the center of their own teaching philosophy. Other participants mentioned their desire to integrate this theme throughout course content as a lens for 
all that they teach. "I need it to be the lens which is much more ... the more awake I am and the more awake everyone is, the more the learning environment supports that". Using this theme as a teaching lens, participants shared that this importance centered around the need to engage students with different perspectives that could challenge their preconceptions. Due to the fact that this study's participants were predominantly white, the data comes from a white identity perspective. There is a larger need, which some participants spoke to, to expand the racial perspectives in DMT pedagogy by increasing representation of diverse faculty members alongside the continued need to diversify resources and experiences in the classroom.

The study's focus group participants also reflected some of the culture and diversity categories from the individual interviews, especially themes of the way in which conversations were "driven by students" bringing an active critical questioning to the classroom as well as educators learning from their mistakes. Within that climate the groups spoke of the need to attend to issues that have "been there forever" with a new sense of urgency. "There seems to me to be, for me, a shift from ideology to action, what some initial action steps might actually be ... and so, you know, none of our programs sit in isolation".

I'm curious about how our teaching can shape, really discipline inquiry ... like doing the hard work to shift language so that how we implement, if we do at all, some of these concepts and ideas ... But I'm hoping to engage each other in that kind of discernment.

\section{Experiential and Embodied Learning}

In order to address and explore these deep issues of awareness and identity, each participant shared a common need for active and embodied learning experiences. There is, as one participant stated, "this blending of theoretical knowledge, experiential learning, and practical skill development that has to become integrated". Several spoke of the "unusual type of educational experience" that can take students by surprise and the need to orient students to this process early on in their learning.

A way that participants have brought experiential learning practices into the classroom is through use of multi-modal approaches, including verbal, movementbased, art-based, didactic, and more. Many participants spoke of the integration of cognitive processing in their classes in the form of journals, creating poems, class discussion, small groups, and partner work. More symbolic methods included giving the class a title or a symbol to concretize or make meaning, creating a body map, engaging in play scenarios, co-creating group rituals, using visual art to process a theme, tracking sensations or images, and utilizing metaphor. Four participants stated that they have students create dances that relate to their development and understanding of DMT concepts. One participant stated, "I often say, 'Can you move the theory, can you talk the theory, and then can you write the theory, can you see the theory?".

Despite the fact that "mind, body, and spirit" and so many parts of the self are involved in the practice of DMT, participants agreed that students often needed "a lot of support really coming into their own bodies". Although students are 
coming from various embodied and dance practices, there is a unique way in which student need to be in their bodies within the structure of DMT principles and this practice was integral to embodied learning.

Participants also spoke about barriers to embodiment in the DMT learning process. One was the brain-centered and didactic mindset of being in a graduate program. Another noted barrier was self-criticism. Participants spoke of the vulnerability of being in one's body and sensing from that place. One participant said, "if that self-critical piece is over reactive you can't be in your body ... The minute you start thinking 'I've got to do a good job here' ... that disconnects you from your body".

As educators, there was a common sharing of the need of the teaching strategies to "create a series of experiences and challenges that help a student integrate" these two realms of theory and in-class experiences, to guide students through ways to translate and integrate DMT theory. These practices allowed students to actively translate experience into clinical practice, "So I like to balance both the experience and the didactic, you know, components ... movements too that can, that the students can start to sort of get curious about themselves and then translate that, being curious as a therapist".

Participants shared a practice of weaving between experience and theory, of moving "quickly between body process (and) the concepts". Some chose to move experientially through a concept first and then process verbally, while others chose to do the opposite, and many spoke of a weaving process between the verbally didactic teaching and movement based experiential teaching. One participant said that she did not feel rigid or bound to class plans, but "I have some kind of idea of how to translate this academic content into the body". Other participants spoke to the embracing of their own creativity in the classroom rather than following a rote plan, modeling this process for students.

The DMT learning process itself was often described as a non-linear one. "It's not always just a linear communication. There's sort of a spiraling way of thinking". Another participant said that, "the material does not sink in fully after one course even if the course is the whole year. So I think it's a recycling thing". The importance of students returning to concepts when they are ready to do so in the process of their own development reflects the non-linear process of their education.

Being able to embrace the non-linear fashion of the DMT learning process also helps to increase the student's flexibility in practice as a core skill as a dance/movement therapist. Participants spoke about the influence of the creative process in their teaching and the nature of "creativity and adaptability". Another area of flexibility for participants was the importance of honoring the process of arriving at concepts and class material.

Participants also spoke of using the classroom as a space for a DMT laboratory. This was seen with teacher-led mock groups, working in triads of therapist/client/ observer, role playing a client for the group to observe, creating sample treatment plans, or presenting cases to the class. These were spaces where students experience being, "the researcher and the researched ... you are the actor and you are the subject of this at the same time ... really looking at developing and observing ego". Another participant spoke of bringing their own clinical experiences for the class. 
I was able to carry that ... into the classroom and say in the classroom look, listen, this is all a lab ... There is not wisdom here. Here we are, we're learning as we go. And I still think that's true. It's, it's about the exchange and the interaction

Focus group participants also agreed on an ontological shift for DMT students where they became more deeply connected to their peers and to their own inner sense of intuition through engaging the body in their learning. The importance of trusting intuition was also reflected in the engagement of and training in the body self. "There is nothing harder ... you're moving from a completely different worldview ... which is trusting a whole different voice ... training your intuition to pick up material from a very different place that you're used to".

They also began to distinguish the different types of experiential and embodied learning that were key to the DMT students' learning process including the use of DMT core principles as pedagogical tools. The core concepts of DMT theory became a way to shape experiences for students.

... the very nature of empathic reflection, although we're not using it for health outcomes, is integral in some ways to our teaching. I mean we can't get away from empathic reflection both as a pedagogical tool as well as ... one of our huge interventions in practice.

This way of shaping the embodied learning process for the DMT students was an active

way of integrating these core concepts into their learning as the classroom was modeled by these three distinct types of embodied learning practices.

\section{Tolerating the Unknown}

Participants spoke of students' ability to tolerate the process-oriented nature of experiential DMT learning. Surprisingly, participants spoke less about the process of the unknown and more about creating a safe space through clear and explicit learning goals. Several spoke about the need to be aware of clarity and being as explicit as possible. "I shouldn't assume knowledge on their part". Others also spoke of the important of invitation and expectation. One participant stated that "invitation has to do with permission and (that) has to do with safety". This safety was built by creating clear definitions of shared language as part of this theme of consistency and clarity.

Seven participants out of 14 spoke about the development of rubrics to measure students' progress. A main challenge that was shared was how to "connect the competencies to what's happening in the classroom". Rubrics were created for assignments, for grading and for more intangible skills like "developing a nonverbal relationship". The more "personal competencies" participants agreed were more difficult to assess and to set clear expectations but there was shared need to engage in these queries. One participants stated that she taught through the lens of "on-boarding through goals ... you know, 'this is the goal of what we're gonna do today'. 
Then exploration ... sharing the learning and then framing it, grounding it through didactic ... variations, or applications, or deepening the work".

Engaging in a classroom culture of questioning was also important to this process of tolerating unknown and uncertainty. "I want you to be in a place where you at least know what you don't know or you know that you don't know". Participants also reinforced questioning in class discussions by saying things like, "I'm glad you asked that" or "What a great conversation!", allowing students to feel more confident in their ability to "not know, as much to know". The goal being coming to a place where "they're really more invested in the questions versus the answers".

This process allowed students to release control offering similar explorations across subjects. Students could then "take this knowledge to the next, and to the next, and to the next class". As process-oriented teaching was unified across courses, students could engage in material in similar ways and increase their tolerance of the unknown in their learning process and the therapeutic process in application.

Focus group participants defined students' increased awareness of the unknown as closely related to the creative and artistic process. "It's about making something out of nothing. It's about process in the moment, moment by moment changes and it's so rich". One participant related this encouragement of the process for students as one of "artistry". "I would just say that's when they become an artist, and that's the creative process ... then how you apply your own creative process within a session is the artistry" Yet another member of this group differentiated the therapist identity within this process as well, where one is "dwelling in a mystery". The integration of artist and therapist self was emphasized without a process of "distilling it out" but focusing of supporting the students to "understand it's integrative aspect in their growth in a new role".

\section{Mentoring and Modeling}

There was a commonly shared idea of the importance of relationship at the core of the educator and student connection. This relationship was facilitated by the participants' focus on modeling their own role as dance/movement therapist within the classroom community. Participants shared the essential nature of modeling personal vulnerability and authenticity of self in the classroom. There was a common theme of bringing fully into their roles as educators, and the positive impact that this practice had on the students. Often what they spoke of as important teacher qualities were reflected in their own sense of self. One participant spoke of the way that mentorship and leadership were integrated, "In order to inspire that connection and then deepen in the work ... I feel like I bring forward my own self energy, presence, authenticity, depth, philosophical underpinnings of humanness".

Bringing one's self into teaching can model for the students a space that is safe for their own self exploration as well. "When I'm participatory and I reveal truth ... about my own self, I'm told that it helps them feel safer and more comfortable to open and avail themselves to the work and the learning and the exploration". Another participant spoke to the importance of modeling taking risks in one's 
learning process, "They're seeing this (person) is vulnerable and open. That's a different experience. And we do, you have to risk".

Participants spoke about group dynamics as another category of modeling in the classroom. Students could gain learning not only from their instructor but also from the active interaction with peers in the classroom and witnessing the way in which their instructor facilitated group interactions. "And frequently they can learn as much from each other as I think they can learn from me. So there is that what I would call group interaction that is part of that learning process".

Participants spoke about shaping their classroom environments in the way that they would a therapeutic space and being explicit to students about this creation of space. "Whatever we are teaching has to be reflected in the way that we're teaching. So it is the modeling of it ... through nonverbal ways of holding the space". Participants also spoke of distilling different clinical choices through classroom experientials. "So we sort of unpack different choices, that I make as a teacher in different moments and how I might do that differently in a group dance therapy context".

Similar to the interview data, in the focus groups mentoring and modeling were referenced to as the need to be "transparent and authentic". Taking this idea a bit further, one group participant spoke about the importance of co-creating and collaborating in the learning process. One elaboration during the focus groups around modeling was the defining of whether to model therapeutic skills in an explicit or implicit way. In these instances, they might even ask the students "what did you notice about how I facilitated today". At times, they felt that "sometimes it's okay to leave it implicit as well ... (but) how to know when to make it explicit like 'this what I'm doing' and how to know when to trust that when they're ready to hear it ... or remember that experience" and reflect on the way that they felt held in a classroom moment.

\section{Teacher and Therapist Parallel}

Participants also spoke about bringing their own skills as therapists into the classroom and their use of skills as a dance/movement therapist to facilitate and operate in the classroom.

Related to this theme, they spoke clearly about the importance of clear boundaries, expectations of the learning process, and when to delineate between therapy and education. "Because it's an experiential program...it is therapeutic because they learn about themselves and their own tendencies. But it's not meant to be therapy". One participant pointed out that staying away from this line and boundary, and restricting personal information can also limit the learning process for students, "which has the, the strength of being able to go through the phases of the techniques and has the weakness that (students) didn't know how to work with real emotion". After an experiential is completed, participants spoke of the importance of verbal processing and meaning making, in order to translate a personal experience into clinical learning.

On other end of the therapeutic continuum for the participants was to create opportunities for challenge as well as safety. They spoke about the moments when 
students needed a push in their learning and development and that their skills as therapists helped them to know when those moments were timely. "So pushing the comfort zone has shown up when the collaboration has hit up against something unexpected or something that was new to each of us- teacher and student". Also, participants spoke about students beginning to facilitate this process for each other, "I've been witness to students challenging each other even more than I challenge them in those moments, you know? And that's pretty great because it's telling me they're ready".

Focus group participants spoke about various therapeutic skills that aided them in classroom facilitation. Some of these included relational skills, improvisational skills, and the ability to read a group. "You know, we work from that perspective, I think which is very different from the teacher who's teaching something else. It's like this understanding of the teaching and learning is a complete reciprocal experience. It's not just about me telling you something, it's not top down at all'. Participants agreed that bringing personal experiences in the classroom back to the professional concept or theme was how they typically held personal information that arose in the classroom.

\section{Discussion}

This study outlined some emerging commonalities in the pedagogy of DMT, while also highlighting the ways in which each educator teaches from their own lived experience and social identity. Qualitative data from the interviews and focus groups built a feedback loop which allowed participants to begin to operationalize some pedagogical concepts in DMT. Themes of self-awareness and growth and mentor and modeling reflected research and literature from earlier in the field's history focusing on the relational aspect to teaching in DMT (Leventhal et al., 2016; Stark, 1980). The data also highlighted the ways in which DMT pedagogy is wide and varied, and similar to the therapeutic process in DMT requires the educator to invite identity exploration into the classroom community. DMT educators pull from their skills as therapists to meet their students in each emerging moment of learning.

\section{Connection to DMT Core Principles}

The emergent themes held an essential connection to the core principles of the DMT field. Participants repeatedly reflected the need to support "whatever we are teaching ... in the way that we're teaching". The core principles of DMT were not only concepts for students to practice in the classroom but also methods that educators used to teach these concepts. Returning to the initial research question, "What core principles of theory and teaching strategies contribute to pedagogical theory in DMT in the United States?" there was a repeated reference to three core DMT principles: empathic reflection, kinesthetic empathy, and the therapeutic movement relationship. 
During the focus group, participants spoke of the use of empathic reflection in teaching. Empathic reflection is one way which the dance/movement therapist "structures a nonjudgmental, supportive environment which is conducive to sharing and growth" (Sandel, 1993, p. 98). Aside from practicing empathic reflection in a skill-based way, there was also a reflection of the importance of the "nonjudgmental, supportive environment" that Sandel (1993, p. 98) defined. Participants spoke about the essential nature of creating space throughout the qualitative themes naming the need for an "unconditional positive classroom environment", an atmosphere of "invitation", and "safe space that is right here". DMT educators brought this essential part of who they were as clinicians into their classroom spaces.

Another core principle that was reflected was kinesthetic empathy, addressing the intersubjective nature of DMT, where the therapist reflects on their own body reaction, using kinesthetic awareness in an embodied relationship (DosamantesBeaudry, 2007; Dosamentes-Alperson, 1984; Tortora, 2005). This is a constant and mindful tracking of sensory and kinesthetic responses that inform the therapeutic process in DMT.

The DMT student needs to engage in constant movement awareness and reflection in their learning process in order to gain understanding of kinesthetic empathy. Participants spoke to the practice of "us(ing) deep parts of ourselves and ... to be fully present at the body/mind level while moving". The embodied engagement through experiential learning practices allows the students to as one participant stated, "stay open and receptive to their own body and the message is there that you know, can translate into their work with clients". Through their own sense of transparency and modeling, the DMT educator brings that openness into their teaching role.

The last core principle that was reflected the therapeutic movement relationship. This concept encompasses the idea of connection and communication through movement and a "shared presence of body, mind, and spirit" (Young, 2017, p. 104). The key component to the therapeutic movement relationship is that there is a multilayered experience of connection that connects to an individual's healing potential (Fischman, 2009). Participants spoke of the depth of relationship that happened in the DMT classroom due to the body's integration in the learning process. Embodied practices deepened the learning process and the building of relationship. Participants stated that relationship and dynamics do not occur "in isolation" but as an integrated part of the diverse and multilayered learning community of which students are a part. This idea of learning in relationship connects to Vygotsky's theories of socio-cultural learning where learners grow through challenge and relationship with peers, especially those who are at different levels of growth and awareness (Daniels, 2003).

The focus on embodied and relational learning also brings with it the need for clarity and containment. As was reflected in the data, participants spoke about the inherent need for clear boundaries and expectations for students to engage in embodied and experiential learning, as well as boundaries around the ways in which they engaged with their own clinical skills as therapist educators. Inviting the self-awareness and identity exploration that is present in the DMT classroom, educators in the study reflected the literature's inquiries around role confusion and the inferred expectation of personal expression in creative arts therapy 
training (Lusebrink, 1989; Emunah, 1989; Butler, 2016). In order to invite students to enter their training as their whole selves, there needs to be extensive work to create shared and cocreated norms in the classroom which the participants spoke to extensively.

These core theoretical principles of empathic reflection, kinesthetic empathy, and the therapeutic movement relationship give the DMT educator the opportunity to bring theory as a lived experience into the classroom. hooks (1991) views on theory as a potentially liberating practice pointed to similar opportunities to connect theory and practice. hooks (1991) believed that theory could be an active process of "critical thinking, of reflection, and analysis" (p. 2). Throughout the themes, participants supported this active engagement with theory, core principles, and expectation in their teaching practice.

No theory, however, lives in isolation or neutrality. Likewise, no individual lives in isolation or neutrality. In this vein, participants in the focus groups spoke of the need to look critically at DMT theories and increase the conversation around including voices from marginalized identities. As one focus group participant stated, she felt the important of shifting "ideology into action". If DMT theory education focuses solely on the early practitioners in the field, primarily white cisgender women, and does not reflect the healing movement practices outside of this select group there is a lost opportunity of theory as representative of the lived experiences of the DMT student (hooks, 1991). Several participants spoke to the ways in which students had brought in their own need for a more critical lens in the classroom, actively advocating for representation of their multiplicity of identities. The educators in the study viewed this as a crucial growing edge in their own teaching and the larger field and a way to support students' feeling seen from their own cultural identity and roots.

One limitation of this study was also a reflection the state of DMT educational programs in 2018-2019; from the 14 participants only two educators did not identify as white and/or cisgender female, other demographic information was not collected. The development of the study's themes needs therefore to be viewed through the cultural lens from which they emerged. As reflected in the literature, the creative arts therapies' theories are built on ontological views of aesthetics, medicine and mental health, and community/societies, which often come from dominant social perspectives. This layering of ontological lenses increases the need to include critical consciousness in pedagogy (Chang, 2009; Caldwell, 2013; Hahna, 2013; Hadley, 2013; Sajnani, 2012). The fields of DMT and DMT education are on a similar aspirational path to their colleagues in the creative arts therapies unpacking the dominant narratives in dance forms, embodied practices, and DMT theories (Hadley, 2013; Kawano \& Chang, 2019) Both the researcher and the study participants, expressed the need to include more voices from educators from a wider lens of sociocultural identities into this discussion and reflected hooks (2003) urging for educators to acknowledging the limits of their own knowledge. As one participant stated "I need it (social justice) to be the lens", this allows the DMT educator to view the qualitative themes identified in this study through the lens of culture, diversity, and expansion for both students and educators. The educators in this study were grateful for the time to connect in the interviews and focus groups, and were 
hopeful to continue active and open discussion around the myriad of themes in DMT education from an inclusive and critical perspective.

\section{Limitations}

Due to the nature of the qualitative research, this study outlines only the experiences of only 14 educators in the US. There are many more adjunct faculty, international educators, and alternate route educators who's experiences are not captured in this inquiry. A future inquiry would be to include these voices in pedagogical discussion.

Also, the researcher is aware of the shift in ADTA approved programs during the period of this research, as they adapt to accommodate a new set of educational standards. A repeated exploration of pedagogical themes would be necessary as these standards become implemented, and as programs follow more competency-based adherence to the educational standards.

Lastly, the events of 2020-2021 have had tremendous effect on the pedagogical practices of DMT educators in the US. Due to the COVID-19 pandemic many educators have had to quickly pivot their embodied and experiential teaching to a virtual or hybrid model. Also, the heightened socio-political landscape of division, racial violence, and injustice have an deep impact on the student and educator experience. These impacts on the education and training environments will also need to be explored moving forward.

\section{Conclusions}

From the generosity and openness of these participants, the study names some of the themes in the landscape of DMT education today and also highlights ways in which the education of DMT needs to grow and shift. Within the landscape of experiential and embodied learning, the DMT student is able to grow and develop with increased awareness of cultural self, professional self, and body self within the relational container of the classroom. Alongside the student's growth process, educators are also constantly examining and re-examining their own unconscious biases and places of not-knowing. Reflected throughout this study, an inherent collaborative relationship was named between the DMT student and educator. Beginning to define the way in which the DMT core principles were integrated in the learning process, both students and educators have the opportunity to step forward from their own identities and self-awareness to bring themselves fully into the learning relationship. This researcher looks forward to future opportunities for continued discussion, growth, and change among educators, with students, and with the larger landscape of DMT as an ever expanding field. 


\section{References}

Allegranti, B. (2009). Embodied performance of sexuality and gender: A feminist approach to dance/ movement psychotherapy and performance practice. Body Movement and Dance in Psychotherapy, 4(1), 17-31.

American Dance Therapy Association. (2017). Standards for education and clinical training. Retrieved from https://adta.org/wp-content/uploads/2015/12/ADTA-Standards-for-Education-and-ClinicalPractice-effective-January-1-2023.pdf

Beardall, N. (2011). Spirals dancing and the spiral integrated learning process: Promoting an embodied knowing. Journal of Applied Arts and Health, 2(1), 7-23.

Beardall, N., Blanc, V., Cardillo, N. J., Karman, S., \& Wiles, J. (2016). Creating the online body: Educating dance/movement therapists using a hybrid low-residency model. American Journal of Dance Therapy, 38(2), 407-428. https://doi.org/10.1007/s10465-016-9228-y

Beardall, N., Brownell, A., Cardillo, N. J., Harmel, P., Karman, S., Marcow-Speiser, V., \& SmulianSiegel, D. (2014). The legacy of Norma canner. American Journal of Dance Therapy, 36(1), 113-124.

Butler, J. (2016). The complex intersection of education and therapy in the drama therapy classroom. Arts in Psychotherapy, 53, 28-35.

Caldwell, C. (2013). Diversity issues in movement observation and assessment. American Journal of Dance Therapy, 35, 183-200.

Chaiklin, S., \& Schmais, C. (1993). The Chace approach to dance therapy. In S. Sandel, S. Chaiklin, \& A. Lohn (Eds.), Foundations of dance/movement therapy: The life and work of Marian Chace (pp. 75-97). Marian Chace Memorial Fund.

Chang, M. (2009). Cultural consciousness and the global context of dance/movement therapy. In S. Chaiklin \& H. Wengrower (Eds.), The art and science of dance/movement therapy: Life is dance ( $\mathrm{p}$. 299316). Routledge.

Chang, M. (2015). Cultural consciousness and the global context of dance/movement therapy. In S. Chaiklin \& H. Wengrower (Eds.), The art and science of dance/movement therapy: Life is dance (pp. 299-316). Routledge.

Cruz, R. (2001). Perspectives on the profession of dance/movement therapy: Past, present, and future. Bulletin of Psychology and the Arts, 2(2), 74-78.

Daniels, H. (2003). Vygotsky and pedagogy. Routledge.

Dewey, J. (1938). Experience and education. Simon and Schuster.

Dirkx, J. (1998). Transformative learning theory in the practice of adult education: An overview. PAACE Journal of Lifelong Learning, 7, 1-14.

Dosamantes-Alperson, E. (1984). Experiential movement psychotherapy. In P. Lewis (Ed.), Theoretical approaches to dance/movement therapy (Vol. II, pp. 145-163). Kendall/Hunt Publishing.

Dosamantes-Beaudry, E. (2007). Somatic transference and countertransference in psychoanalytic intersubjective dance/movement therapy. American Journal of Dance Therapy, 29(2), 73-89.

Emunah, R. (1989). The use of dramatic enactment in the training of drama therapists. Arts in Psychotherapy, 16, 29-36.

Fischman, D. (2009). Therapeutic relationships and kinesthetic empathy. In S. Chaiklin \& H. Wengrower (Eds.), The art and science of dance/movement therapy: Life is dance (pp. 33-53). Routldge.

Freire, P. (2000). Pedagogy of the oppressed. Bloomsburg Press.

Goodill, S. \& Schelly Hill, E. (2017). The body knows: Integrating movement elicitation in qualitative research. In: Proceedings of the American Dance Therapy Association, San Antonio. pp. 177-181

Hadley, S. (2013). Dominant narratives: Complicity and the need for vigilance in the creative arts therapies. Arts in Psychotherapy, 40(4), 373-381.

Hahna, N. (2013). Towards an emancipatory practice: Incorporating feminist pedagogy in the creative arts therapies. Arts in Psychotherapy, 40, 436-440.

Hervey, L. (2007). Embodied ethical decision making. American Journal of Dance Therapy, 29(2), 91-108. https://doi.org/10.1007/s10465-007-9036-5

Hervey, L., \& Stuart, L. (2012). Cultural competency education in approved dance/movement therapy graduate programs. American Journal of Dance Therapy, 34(2), 85-98.

hooks, b. (1991). Theory as a liberatory practice. Yale Journal of Law and Feminism, 4(1), 1-13. Retrieved from https://digitalcommons.law.yale.edu/yjlf/vol4/iss 1/2/.

hooks, b. (1994). Teaching to transgress: Education as the practice of freedom. Routledge. 
hooks, b. (2003). Teaching community: A pedagogy of hope. Routledge.

Kawano, T., \& Chang, M. (2019). Applying critical consciousness to dance/movement therapy pedagogy and the politics of the body. American Journal of Dance Therapy, 41(2), 234-255. https://doi.org/ 10.1007/s10465-019-09315-5

Kolb, A., \& Kolb, D. (2005). Learning styles and learning spaces: Enhancing experiential learning in higher education. Academy of Management Learning and Education, 4(2), 193-212.

Kolb, D. (1984). Experiential learning. Prentice Hall.

Leventhal, M., Cathcart, J., Chaiklin, S., Chodorow, J., DiPalma, E., Koch, N., \& Harris, D. (2016). Embodied proteges: Second generation dance/movement therapists on mentorship with the founders. American Journal of Dance Therapy, 38(2), 164-182.

Meekums, B. (2006). Embodiment in dance movement therapy training and practice. In H. Payne (Ed.), Dance movement therapy: Theory, research, and practice (pp. 167-183). Routledge.

Mezirow, J., \& Taylor, E. (2009). Transformative learning in practice: Insights from community workplace and higher education. Jossey-Bass.

Miles, A. (2002) Feminist perspectives in globalization and integrative transformative learning. In: E. O'Sullivan, A. Morrell, \& M. A. O'Connor. (Eds.), Expanding the boundaries of transformative learning: Essays on theory and praxis (pp. 21-33). New York, Palgrave

O'Sullivan, E. (2002) The project and vision of transformative education. In E. O'Sullivan, A. Morrell, \& M.A. O'Connor. (Eds.), Expanding the boundaries of transformative learning: Essays on theory and praxis (pp. 4-12). Palgrave.

Payne, H. (2008). Supervision of dance movement therapy: An overview. In H. Payne (Ed.), Supervision of dance movement therapy: A practitioner's handbook (pp. 1-17). Routlege.

Sandel, S. (1993). The process of empathic reflection in dance therapy. In S. Sandel, S. Chaiklin, \& A. Lohn (Eds.), Foundations of dance/movement therapy: The life and work of Marian Chace (pp. 98-120). Marian Chace Memorial Fund.

Schmais, C. (2004). The journey of a dance therapy teacher. Marian Chace Foundation.

Selby, D. (2002). The signature of the whole: Radical interconnectedness and its implications for global and environmental education. In E. O'Sullivan, A. Morrell, \& M. A. O'Connor (Eds.), Expanding the boundaries of transformative learning: Essays on theory and praxis (pp. 77-93). Palgrave.

Stark, A. (1980). The evolution of professional training in the American Dance Therapy Association. American Journal Dance Therapy, 3(2), 12-19.

Thomas, N., \& Blanc, V. (2021). Break it then build again: An arts based duoethnographic pilot reconstructing music therapy and dance/movement therapy histories. The Arts in Psychotherapy, 73, 1-9. https://doi.org/10.1016/j.aip.2021.101765

Tortora, S. (2005). The dancing dialogue. Brooks.

Vygotsky, L. S. (1978). Mind in society: The development of higher psychological processes. Harvard University Press.

Publisher's Note Springer Nature remains neutral with regard to jurisdictional claims in published maps and institutional affiliations.

Valerie Blanc has been a part of the Lesley University dance/movement therapy specialization faculty since 2011 and as a core faculty since 2018. She is currently the Coordinator of the Dance/Movement Therapy specialization working with a vibrant team of innovative educators. She teaches in both the on campus and hybrid low residency distance learning programs and was a part of the design team to create the low residency curriculum. Her teaching work includes the DMT Theories courses, Clinical Applications and Supervision, and the span of Body Movement Observation courses. She has been an integral part of curricular redesign in these courses, with a focus on diversity, equity, and inclusion within the dance/movement therapy pedagogy both at Lesley and nationally. Currently, Valerie is a dance/movement therapist in private practice specializing in work with young children and their families as well as and clinical supervision. Her clinical experience has centered around work with children with a focus on work with attachment patterns and sensory integration work-especially with the deaf population. She has extensive experience in inpatient psychiatric work with children and adolescents as well as community mental health support. She worked for 13 years with the Boston Children's Foundation implementing the Rainbowdance and $\mathrm{CBI}$ programs in acute trauma response and resiliency building utilizing the expressive 
therapies. She acted as a lead trainer in the Rainbowdance and CBI programs, in response to acute community trauma.Valerie's research interests center around the pedagogical practices of dance/movement therapy and building pedagogical theory in the field. Her recent research studies have explored the dance/ movement therapy hybrid low residency student's sense of embodied presence in their core courses as well as pedagogical practices of dance/movement therapy educators in ADTA approved programs. She was also part of the planning committee for the 2020 international Pathways to Practice: Conversations in Arts Therapies Education conference, as well as co-leading ongoing departmental workshops exploring pedagogical themes in the expressive therapies at Lesley. In collaboration with music therapy colleagues she has also explored a critical perspective of the histories of dance/movement therapy and music therapy through a duo-ethnographic and arts based lens. With national and local leadership in professional organizations, she has acted on the American Dance Therapy Association's Committee on Approval, collaborating with educators across the United States to assure educational standards for DMT education. She is also an active member of the ADTA Education Committee where she currently asks on several task forces addressing educational standards revision, critical examination of movement observation lenses in DMT, and revision of the application process for board certification in the field. 